\title{
Adubação de cultivares de feijoeiro comum em várzeas tropicais ${ }^{1}$
}

\author{
Adriano Stephan Nascente ${ }^{2}$, João Kluthcouski ${ }^{2}$, \\ Carlos Alexandre Costa $\mathrm{Crusciol}^{3}$, Tarcísio Cobucci ${ }^{2}$, Priscila de Oliveira ${ }^{4}$
}

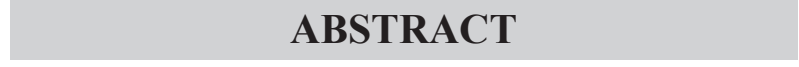

Fertilization of common bean

cultivars in tropical lowlands

The bean crop has a high economic and social importance for the Brazilian population. However, some aspects should be improved in its cropping system, such as the plants fertilization management. The common bean sub-irrigation, in the rice intercropping, has been a viable alternative for grain yield, in the lowland ecosystem. However, there are just a few studies on fertilization in tropical lowland conditions. Thus, this study aimed at evaluating the yield of common bean cultivars grown under tropical lowland conditions and sub-irrigation, in Lagoa da Confusão, Tocantins State, Brazil, in the winter of 2008, by using different fertilizers sources, doses and splittings. The experimental design was randomized blocks, in a factorial scheme (cultivars $\mathrm{x}$ forms of fertilization), with cultivars divided into groups (black, carioca and special). The common bean yield was higher with the early nitrogen fertilization, and even higher when it was combined with potassium in topdressing fertilization, being the Ouro Negro (black group), Pitoco (carioca group) and Cranberry and BRS Embaixador (special group) the cultivars that reached the highest grain yields. When the recommended fertilization was used, Ouro Negro (black group), Carioca (carioca group) and Jalo Precoce and BRS Embaixador (special group) reached the highest grain yield, for each grain group. Yield was higher for the black group cultivars, when compared to the carioca and special groups.

KEY-WORDS: Phaseolus vulgaris L.; nitrogen; fertilizers; early fertilization.

\section{INTRODUÇÃO}

A cultura do feijão (Phaseolus vulgaris L.) possui grande importância econômica, para o Brasil, uma vez que a área cultivada, na safra 2010/2011, foi de cerca de 4,01 milhões de hectares, o que correspondeu a uma produção de 3,8 milhões de

\section{RESUMO}

A cultura do feijão possui grande importância econômica e social, para a população brasileira. Entretanto, há aspectos que devem ser melhorados em seu cultivo, como o manejo de adubação das plantas. A subirrigação do feijoeiro, na entressafra do arroz, tem se mostrado alternativa viável para a produção de grãos, no ecossistema de várzea. Entretanto, poucos são os trabalhos realizados sobre adubação em condições de várzeas tropicais. Neste sentido, este estudo objetivou avaliar a produtividade de cultivares de feijoeiro comum, sob condições de várzeas tropicais e subirrigação, em Lagoa da Confusão (TO), na safra de inverno de 2008, submetidas a diferentes fontes, doses e parcelamentos de fertilizantes. Utilizou-se o delineamento experimental em blocos ao acaso, em esquema fatorial (cultivares x formas de adubação), com as cultivares separadas por grupos (preto, carioca e especial). A produtividade do feijoeiro foi maior com a antecipação da adubação nitrogenada, e ainda maior quando esta foi combinada com a suplementação de potássio em cobertura, sendo que Ouro Negro (grupo preto), Pitoco (grupo carioca) e Cranberry e BRS Embaixador (grupo especial) foram as cultivares mais produtivas. Com a utilização da adubação recomendada, Ouro Negro (grupo preto), Carioca (grupo carioca) e Jalo Precoce e BRS Embaixador (grupo especial) foram as mais produtivas, para cada grupo. As cultivares do grupo preto foram mais produtivas que as dos grupos carioca e especial.

PALAVRAS-CHAVE: Phaseolus vulgaris L.; nitrogênio; fertilizantes; adubação antecipada.

toneladas (Conab 2011). Entretanto, apesar da sua importância, ainda é constatada baixa utilização de tecnologia em seu cultivo, principalmente na primeira e segunda safras, resultando em baixa produtividade, equivalente a $945 \mathrm{~kg} \mathrm{ha}^{-1}$ (Conab 2011). A terceira safra caracteriza-se como a mais tecnificada, sendo que, em 2010/2011, a produtividade média alcançou

1. Trabalho recebido em jul./2012 e aceito para publicação em nov./2012 (nº registro: PAT 19448).

2. Embrapa Arroz e Feijão, Santo Antônio de Goiás, GO, Brasil.E-mails: adriano.nascente@embrapa.br, joao.kluthcouski@embrapa.br, tarcisio.cobucci@embrapa.br.

3. Universidade Estadual Paulista (Unesp), Faculdade de Ciências Agronômicas, Departamento de Produção e Melhoramento Vegetal, Botucatu, SP, Brasil.E-mail: crusciol@fca.unesp.br.

4. Embrapa Cerrados, Planaltina, DF, Brasil.E-mail: priscila.oliveira@embrapa.br. 
$3.607 \mathrm{~kg} \mathrm{ha}^{-1}$ (Conab 2011), indicando que há incremento na produtividade de grãos, em razão do uso de tecnologia.

Dentre os aspectos que devem ser melhorados, na cultura do feijoeiro, está o manejo de adubação das plantas, uma vez que, com o fornecimento adequado e equilibrado de nutrientes, pelo uso de fertilizantes, pode-se obter aumentos significativos na produtividade de grãos (Miranda et al. 2000, Andrade et al. 2004, Arf et al. 2011). Entretanto, para se auferir melhores resultados, é preciso adubar equilibradamente e posicionar o adubo corretamente, em relação às sementes e à superfície do solo (Meira et al. 2005, Soratto et al. 2005, Farinelli et al. 2006a e 2006b, Kluthcouski et al. 2006, Crusciol et al. 2007, Valderrama et al. 2009, Sant'ana et al. 2010, Afonso et al. 2011, Arf et al. 2011, Barbosa et al. 2011).

No Brasil, existem diferentes ecossistemas para o cultivo do feijoeiro, sendo que, no inverno, se destacam as várzeas tropicais do Tocantins, que possuem peculiaridades que as tornam um excelente local para a produção de sementes de feijão, tais como menor custo de produção, baixa umidade relativa do ar e utilização da irrigação por subirrigação (que desfavorece a ocorrência de doenças foliares) e por inundação do arroz, no verão, suprimindo os fitopatógenos com origem no solo (Aidar et al. 2002). $\mathrm{Na}$ irrigação pelo manejo do lençol freático, ou subirrigação, a umidade atinge as raízes das plantas por ascensão capilar. Assim, por não molhar as folhas, este método de irrigação não favorece a dispersão dos patógenos da parte aérea (Aidar et al. 2002).

Entretanto, ainda existem poucas informações sobre o manejo da adubação do feijoeiro, nesse ecossistema, bem como sobre o comportamento de cultivares de feijoeiro comum, nesse tipo de ambiente. Neste sentido, este trabalho baseou-se nas seguintes hipóteses: a) a identificação do momento adequado para realizar a adubação nitrogenada, nas várzeas tropicais, durante a safra de inverno, sob subirrigação, talvez possa propiciar aumento significativo na produtividade do feijoeiro comum; b) por existirem poucos estudos sobre adubação sob subirrigação, nas várzeas tropicais, mesmo utilizando-se a adubação tradicional recomendada pelos boletins oficiais, é provável que a suplementação de alguns nutrientes, em conjunto com a adubação antecipada do $\mathrm{N}$ (todo na base), possa acarretar incremento na produtividade da cultura; c) dentre os grupos de cultivares, é provável que, nas várzeas tropicais, existam materiais para os quais a utilização da adubação tradicional recomendada pelos boletins oficiais seja suficiente para atingir as máximas produtividades. Por outro lado, provavelmente, outros materiais talvez exijam um manejo diferenciado da adubação, bem como suplementação de nutrientes, para atingir maiores produtividades.

Assim, este trabalho objetivou avaliar a produtividade de grãos de cultivares de feijoeiro comum dos tipos preto, carioca e especial, cultivadas nas condições de várzeas tropicais do Tocantins, sob subirrigação, na safra de inverno, submetidas a diferentes fontes, doses e parcelamentos de fertilizantes.

\section{MATERIAL E MÉTODOS}

O experimento foi instalado na Fazenda Arco-Íris, localizada no município de Lagoa da Confusão (TO), em área sob domínio do ecossistema de várzea tropical, com clima local do tipo B1wA'a', segundo a classificação de Köppen, precipitação média anual de $1.700 \mathrm{~mm}$, temperatura média de $27,5^{\circ} \mathrm{C}$ e umidade relativa do ar de $76 \%$, com verão chuvoso e inverno seco.

O solo foi classificado como Gleissolo hidromórfico, de cor acinzentada, ácido a fortemente ácido, com pH entre 4,5 e 5,0 e CTC alta, devido, principalmente, à presença elevada de matéria orgânica (Embrapa 1999). A textura é média ou argilosa, em todos os horizontes (Aidar et al. 2002). Os atributos químicos foram determinados antes da instalação do experimento, na camada de $0,0-0,20 \mathrm{~m}$, com os seguintes resultados: $\mathrm{pH}$ (água) $=5,0 ; \mathrm{MO}=$ $46 \mathrm{~g} \mathrm{~kg}^{-1} ; \mathrm{P}=26,3 \mathrm{mg} \mathrm{dm}^{-3} ; \mathrm{K}=187 \mathrm{mg} \mathrm{dm}^{-3} ; \mathrm{Ca}=$ $3,15 \mathrm{cmol}_{\mathrm{c}} \mathrm{dm}^{-3} ; \mathrm{Mg}=1,15 \mathrm{cmol}_{\mathrm{c}} \mathrm{dm}^{-3} ; \mathrm{H}+\mathrm{Al}=$ $10,21 \mathrm{cmol} \mathrm{dm}^{-3} ; \mathrm{Cu}=1,2 \mathrm{mg} \mathrm{dm}^{-3} ; \mathrm{Zn}=5,1 \mathrm{mg} \mathrm{dm}^{-3}$; $\mathrm{Fe}=52 \mathrm{mg} \mathrm{dm}^{-3} ; \mathrm{e} \mathrm{Mn}=13 \mathrm{mg} \mathrm{dm}^{-3}$. Com base nos resultados, o solo foi caracterizado como de média a alta fertilidade, com alto teor de matéria orgânica (Fageria et al. 1994).

A área esteve sob sistema plantio direto (SPD) por dois anos, sendo cultivada com arroz, na safra de verão, e feijão, no inverno. A semeadura foi realizada em 05 de junho de 2008, em SPD, na densidade de 17 sementes $\mathrm{m}^{-1}$, com espaçamento entre as linhas de $0,45 \mathrm{~m}$. Na adubação de semeadura, aplicou-se $381 \mathrm{~kg} \mathrm{ha}^{-1}$ da fórmula 04-28-12 ( $\left.\mathrm{N}_{-} \mathrm{P}_{2} \mathrm{O}_{5}-\mathrm{K}_{2} \mathrm{O}\right)$, em todos os tratamentos. $\mathrm{O}$ controle de plantas daninhas e pragas foi realizado de acordo com as necessidades, utilizando-se os produtos químicos recomendados 
para a cultura, dispensando-se o controle químico preventivo de doenças, uma vez que o ambiente não propiciava condições favoráveis ao seu desenvolvimento (Aidar et al. 2002).

Utilizou-se o delineamento em blocos ao acaso, em esquema fatorial (cultivares $\mathrm{x}$ formas de adubação), com quatro repetições, sendo as parcelas constituídas por quatro linhas de 4,0 m de comprimento. Foram avaliadas, separadamente por grupos, as cultivares de feijoeiro comum com grãos do tipo preto (BRS Supremo, Ouro Negro e BRS Valente), carioca (Pitoco, Rudá, Carioca, BRS Pontal, BRS Horizonte, Pérola, Emgopa e BRS Requinte) e especial (Jalo Precoce, Jalo EEP, Iraí, BRS Radiante, BRS Executivo, BRS Embaixador, WAF 75 e Cranberry).

As formas de adubação testadas foram: a) testemunha sem nitrogênio suplementar, somente o contido no adubo formulado aplicado na semeadura (15 kg N ha-1); b) $60 \mathrm{~kg} \mathrm{ha}^{-1}$ de $\mathrm{N}$ incorporado em cobertura, aos 12 dias após a emergência (DAE) do feijão, sendo, esta, a adubação recomendada (Sousa \& Lobato 2003); c) $30 \mathrm{~kg} \mathrm{ha}^{-1}$ de N aplicado no mesmo dia, imediatamente antes da operação de semeadura do feijão, e $30 \mathrm{~kg} \mathrm{ha}^{-1}$ de $\mathrm{N}$ incorporado em cobertura, aos 12 DAE; d) $60 \mathrm{~kg} \mathrm{ha}^{-1}$ de $\mathrm{N}$ aplicado no mesmo dia, imediatamente antes da operação de semeadura do feijão; e) $60 \mathrm{~kg} \mathrm{ha}^{-1}$ de $\mathrm{N}$ aplicado no mesmo dia, imediatamente antes da operação de semeadura do feijão, e $150 \mathrm{~kg} \mathrm{ha}^{-1}$ de termofostato yoorin, sendo metade incorporada ao solo e outra metade aplicada a lanço, ambas antes da semeadura do feijão; f) $60 \mathrm{~kg} \mathrm{ha}^{-1}$ de $\mathrm{N}$ aplicado no mesmo dia, imediatamente antes da operação de semeadura do feijão, e $50 \mathrm{~kg} \mathrm{ha}^{-1}$ de FTE BR 12, sendo incorporado antes da semeadura do feijão; g) $60 \mathrm{~kg} \mathrm{ha}^{-1}$ de $\mathrm{N}$ aplicado no mesmo dia, imediatamente antes da operação de semeadura do feijão, e $350 \mathrm{~kg} \mathrm{ha}^{-1}$ de 04-28-12, antes da semeadura, além dos $350 \mathrm{~kg} \mathrm{ha}^{-1}$ aplicados simultaneamente à semeadura, em todos os tratamentos; h) $60 \mathrm{~kg} \mathrm{ha}^{-1}$ de $\mathrm{N}$ aplicado no mesmo dia, imediatamente antes da operação de semeadura do feijão, e $60 \mathrm{~kg} \mathrm{ha}^{-1}$ de $\mathrm{K}_{2} \mathrm{O}$, em cobertura, aos 12 DAE.

A fonte de nitrogênio utilizada foi a ureia (44\% de N) e a incorporação dos fertilizantes foi realizada mecanicamente, com o uso de adubadora de discos, à profundidade de $5,0 \mathrm{~cm}$. A colheita foi semimecanizada, com arranquio manual das plantas e trilha mecanizada, colocando-se os grãos para secagem, sendo, estes, posteriormente pesados e transformados para $\mathrm{kg} \mathrm{ha}^{-1}$, a $130 \mathrm{~g} \mathrm{~kg}^{-1}$ de umidade.
Para avaliar o efeito do fator cultivares x épocas de aplicação de N, realizou-se análise de variância, com teste de comparação de médias apenas para os tratamentos 1,2, 3 e 4, separando-os por grupos de cultivares (preto, carioca e especial). Para avaliar $\mathrm{o}$ efeito do fator cultivares $\mathrm{x}$ fertilizantes suplementares, realizou-se análise de variância, com teste de comparação de médias apenas para os tratamentos 4 , $5,6,7$ e 8 , que também foram separados por grupos de cultivares. O teste comparativo de média utilizado foi o Tukey $(\mathrm{p} \leq 0,05)$. Para realização das análises estatísticas, utilizou-se o software estatístico SAS.

Dessa forma, para o fator cultivares $\mathrm{x}$ épocas de aplicação de $\mathrm{N}$, foram utilizados os esquemas fatoriais $3 \times 4$ (grupo preto), $8 \times 4$ (grupo carioca) e $8 \times 4$ (grupo especial). Para o fator cultivares $x$ fertilizantes suplementares, foram utilizados os esquemas fatoriais $3 \times 5$ (grupo preto), $8 \times 5$ (grupo carioca) e $8 \times 5$ (grupo especial).

Adicionalmente, foi realizada uma análise de variância e teste comparativo de médias Tukey $(\mathrm{p} \leq 0,05)$, para avaliar os grupos de cultivares preto (BRS Supremo, Ouro Negro e BRS Valente), carioca (Pitoco, Rudá, Carioca, BRS Pontal, BRS Horizonte, Pérola, Emgopa e BRS Requinte) e especial (Jalo Precoce, Jalo EEP, Iraí, BRS Radiante, BRS Executivo, BRS Embaixador, WAF 75 e Cranberry), em fatorial 3x8 (grupo de cultivares x tipo de adubação), e uma avaliação da média geral das produtividades das cultivares, em cada tipo de adubação.

\section{RESULTADOS E DISCUSSÃO}

\section{Adubação nitrogenada}

Analisando-se os dados de épocas de aplicação de nitrogênio, constatou-se, por meio da análise de variância, que houve interação entre os fatores cultivares e adubação, em todos os grupos de cultivares de feijão (Tabela 1). Assim, para as cultivares do grupo preto BRS Supremo e Ouro Negro, foram constatadas as maiores produtividades, quando houve aplicação de metade do $\mathrm{N}$ antecipado e metade em cobertura. Entretanto, para a cultivar BRS Valente, verificou-se que a maior produtividade de grãos ocorreu com a aplicação de todo o $\mathrm{N}$ de forma antecipada, um dia antes da semeadura do feijão (Tabela 1). Isto evidencia a possibilidade de antecipação da adubação nitrogenada no ecossistema (várzeas tropicais) e no sistema de produção plantio direto. 
Tabela 1. Produtividade de grãos de feijoeiro comum irrigado por subirrigação, em função de cultivares e épocas de aplicação de fertilizantes nitrogenados, no cultivo de inverno (Lagoa da Confusão, TO, 2008).

\begin{tabular}{|c|c|c|c|c|}
\hline \multirow{2}{*}{ Cultivares } & \multicolumn{4}{|c|}{ Épocas de aplicação de nitrogênio* } \\
\hline & 1. Sem $\mathrm{N}^{(1)}$ & 2. $\mathrm{N} \mathrm{cob}^{(2)}$ & 3. $\mathrm{N}$ ant $+\mathrm{N} \operatorname{cob}^{(3)}$ & 4. $\mathrm{N}$ ant ${ }^{(4)}$ \\
\hline Grão tipo preto & \multicolumn{4}{|c|}{ - Produtividade $\left.(\mathrm{kg} \mathrm{ha})^{-1}\right)$} \\
\hline BRS Supremo & $1.863 \mathrm{bC}^{* *}$ & $2.223 \mathrm{bB}$ & $2.840 \mathrm{aA}$ & $2.354 \mathrm{bB}$ \\
\hline Ouro Negro & $2.729 \mathrm{aB}$ & $2.480 \mathrm{aC}$ & $2.883 \mathrm{aA}$ & $2.699 \mathrm{aB}$ \\
\hline BRS Valente & $1.757 \mathrm{bC}$ & $1.991 \mathrm{cB}$ & $1.776 \mathrm{bC}$ & $2.651 \mathrm{aA}$ \\
\hline \multicolumn{5}{|l|}{ Grão tipo carioca } \\
\hline Pitoco & $2.152 \mathrm{aD}$ & $2.279 \mathrm{bC}$ & $2.489 \mathrm{bB}$ & $2.775 \mathrm{aA}$ \\
\hline Rudá & $1.869 \mathrm{bC}$ & $2.315 \mathrm{bB}$ & $2.591 \mathrm{abA}$ & $2.536 \mathrm{bcA}$ \\
\hline Carioca & $2.088 \mathrm{aB}$ & $2.588 \mathrm{aA}$ & $2.642 \mathrm{aA}$ & $2.580 \mathrm{bA}$ \\
\hline BRS Pontal & $2.097 \mathrm{aB}$ & $2.392 \mathrm{bA}$ & $2.186 \mathrm{cB}$ & $2.149 \mathrm{~dB}$ \\
\hline BRS Horizonte & $1.494 \mathrm{cC}$ & $1.937 \mathrm{cB}$ & $2.477 \mathrm{bA}$ & $1.945 \mathrm{eB}$ \\
\hline Pérola & $2.024 \mathrm{aC}$ & $2.346 \mathrm{bB}$ & $2.533 \mathrm{abA}$ & $2.453 \mathrm{cAB}$ \\
\hline Emgopa & $1.507 \mathrm{cD}$ & $2.317 \mathrm{bA}$ & $1.858 \mathrm{dC}$ & $2.037 \mathrm{deB}$ \\
\hline BRS Requinte & $1.256 \mathrm{dC}$ & $1.793 \mathrm{~dB}$ & $2.300 \mathrm{cA}$ & $1.820 \mathrm{fB}$ \\
\hline \multicolumn{5}{|l|}{ Grão tipo especial } \\
\hline Jalo Precoce & $1.322 \mathrm{bD}$ & $1.963 \mathrm{aB}$ & $1.816 \mathrm{bC}$ & $2.164 \mathrm{bA}$ \\
\hline Jalo EEP & $918 \mathrm{eB}$ & $1.318 \mathrm{eA}$ & $1.394 \mathrm{eA}$ & $1.368 \mathrm{eA}$ \\
\hline Iraí & $996 \mathrm{deC}$ & $1.816 \mathrm{bcA}$ & $1.662 \mathrm{cB}$ & $1.735 \mathrm{dAB}$ \\
\hline BRS Radiante & $1.640 \mathrm{aB}$ & $1.626 \mathrm{~dB}$ & $1.504 \mathrm{deC}$ & $1.928 \mathrm{cA}$ \\
\hline BRS Executivo & $977 \mathrm{deC}$ & $1.343 \mathrm{eB}$ & $1.413 \mathrm{eB}$ & $1.782 \mathrm{dA}$ \\
\hline BRS Embaixador & $1.409 \mathrm{bC}$ & $1.863 \mathrm{abB}$ & $1.957 \mathrm{aB}$ & $2.338 \mathrm{aA}$ \\
\hline WAF 75 & $1.192 \mathrm{cC}$ & $1.680 \mathrm{~dB}$ & $1.591 \mathrm{cdB}$ & $1.991 \mathrm{cA}$ \\
\hline \multirow[t]{3}{*}{ Cranberry } & $1.093 \mathrm{cdD}$ & $1.743 \mathrm{cdC}$ & $1.909 \mathrm{abB}$ & $2.248 \mathrm{abA}$ \\
\hline & \multicolumn{4}{|c|}{ Anava (Probabilidade de teste F) } \\
\hline & Preto & & & Especial \\
\hline Cultivares (C) & $<0,001$ & & & $<0,001$ \\
\hline Fertilização (F) & 0,0231 & & & $<0,001$ \\
\hline $\mathrm{C} \times \mathrm{F}$ & 0,0432 & & & 0,0379 \\
\hline C.V. (\%) & 3,42 & & & 8,96 \\
\hline
\end{tabular}

Por outro lado, deve ser ressaltada a capacidade distinta das cultivares, quanto à absorção de $\mathrm{N}$, pois, sem a aplicação do nutriente, a cultivar Ouro Negro produziu mais de $850 \mathrm{~kg} \mathrm{ha}^{-1}$ de grãos, em relação às demais cultivares, evidenciando que $o$ fornecimento de $15 \mathrm{~kg} \mathrm{ha}^{-1} \mathrm{de} \mathrm{N}$, via formulado, na semeadura, e, provavelmente, o elevado teor de matéria orgânica do solo (4,6\%) (Fageria et al. 1994) foram suficientes para esta cultivar produzir $2.729 \mathrm{~kg} \mathrm{ha}^{-1}$, sem o fornecimento extra de N. Da mesma forma, Soratto et al. (2003), Meira et al. (2005), Binotti et al. (2007) e Arf et al. (2011), trabalhando com cultivares do grupo carioca, também não observaram diferenças na produtividade do feijoeiro, com relação às épocas de aplicação do nitrogênio. Neste sentido, deve-se destacar a estabilidade produtiva desta cultivar, que foi a mais produtiva em todas as épocas de aplicação de nitrogênio.

Os maiores incrementos na produtividade de grãos, com a aplicação de N, ocorreram com as cultivares BRS Supremo e BRS Valente (Tabela 1). Segundo Santos \& Fageria (2008), a demanda de N pelo feijoeiro, em várzeas, é maior que nos sistemas tradicionais de cultivo, em terras altas, o que reforça, em parte, a constatação do incremento na produtividade de grãos da cultura, em virtude da elevação das doses deste nutriente $\left(60 \mathrm{~kg} \mathrm{ha}^{-1}\right.$ de $\mathrm{N}$, além do aplicado no adubo formulado).

Resultados semelhantes foram obtidos por outros autores, que, também, obtiveram incrementos significativos na produtividade de grãos do feijoeiro, com o incremento da fertilização nitrogenada, cujas res- 
postas máximas foram obtidas nas doses de $103 \mathrm{~kg} \mathrm{ha}^{-1}$ (Santos et al. 2003), $164 \mathrm{~kg} \mathrm{ha}^{-1}$ (Meira et al. 2005), $75 \mathrm{~kg} \mathrm{ha}^{-1}$ (Soratto et al. 2005), $185 \mathrm{~kg} \mathrm{ha}^{-1}$ (Farinelli et al. 2006a e 2006b), $95 \mathrm{~kg} \mathrm{ha}^{-1}$ (Crusciol et al. 2007), $129 \mathrm{~kg} \mathrm{ha}^{-1}$ (Valderrama et al. 2009), $62 \mathrm{~kg} \mathrm{ha}^{-1}$ (Sant'ana et al. 2010), $80 \mathrm{~kg} \mathrm{ha}^{-1}$ (Afonso et al. 2011) e $143 \mathrm{~kg} \mathrm{ha}^{-1}$, para a cultivar Pérola, e $134 \mathrm{~kg} \mathrm{ha}^{-1}$, para a cultivar IAC Carioca Eté (Barbosa et al. 2011).

Quanto às cultivares do grupo carioca (Tabela 1), destaca-se a estabilidade produtiva da cultivar Carioca, em todas as épocas de aplicação de N. Quanto à época de aplicação de N, fica evidente que as cultivares BRS Pontal e Emgopa apresentam melhor desempenho com a aplicação de todo o $\mathrm{N}$ em cobertura, diferindo, esta época, das demais. Isto pode ser explicado pela hipótese de que estas cultivares possuam baixa capacidade de absorver $\mathrm{N}$, nos estádios iniciais de desenvolvimento, em decorrência do menor desenvolvimento radicular ou da baixa atividade dos carregadores dos sítios de absorção, na fase inicial de plântulas.

A aplicação de metade do $\mathrm{N}$, ou sendo ele totalmente antecipado, não satisfaz às necessidades dessas cultivares, quando começam a demandar pelo nutriente (Santos et al. 2003). Entretanto, para todas as demais cultivares, fica clara a possibilidade de aplicação de $\mathrm{N}$ total e/ou parcialmente antecipado, que, para algumas cultivares, proporcionou maior produtividade (Pitoco, Rudá, BRS Horizonte, Pérola e BRS Requinte) (Tabela 1). A exceção foi a cultivar Carioca, que, para a simples aplicação de N, independentemente da época, incrementou a produtividade de grãos. Segundo Oliveira et al. (2010), a aplicação de $\mathrm{N}$ mineral, na semeadura ou no estádio de plântulas do feijão, proporciona maior produtividade de grãos que a aplicação em época oficialmente recomendada.

$\mathrm{Na}$ ausência da aplicação de $\mathrm{N}$, as cultivares Pitoco, Carioca, BRS Pontal e Pérola alcançaram as maiores produtividades de grãos (Tabela 1), podendo ser consideradas os materiais com maior estabilidade produtiva, nestas condições. Estes resultados permitem inferir que estas cultivares tiveram melhor adaptação às condições das várzeas tropicais do Tocantins e possuem maior capacidade na absorção de $\mathrm{N}$ do solo, em relação às demais, pois o fornecimento de $15 \mathrm{~kg} \mathrm{ha}^{-1}$ de $\mathrm{N}$, na semeadura, juntamente com o $\mathrm{N}$ presente no solo, devido ao elevado teor de matéria orgânica $(4,6 \%)$, foram suficientes para estas cultivares produzirem acima de $2.000 \mathrm{~kg} \mathrm{ha}^{-1}$ de grãos, sem o fornecimento extra de $\mathrm{N}$.
Para o grupo especial (Tabela 1), com exceção das cultivares Jalo EEP e Iraí, a aplicação de todo o N antecipadamente promoveu maiores produtividades de grãos. No entanto, houve diferença entre as cultivares sob este manejo, destacando-se as cultivares BRS Embaixador, Cranberry e Jalo Precoce, que apresentaram as maiores produtividades de grãos.

$\mathrm{Na}$ ausência da aplicação de $\mathrm{N}$, as cultivares Jalo Precoce, BRS Embaixador e, notadamente, BRS Radiante foram as mais produtivas, diferindo das demais deste grupo (Tabela 1), porém, com produtividade inferior a $2.000 \mathrm{~kg} \mathrm{ha}^{-1}$, superada por algumas cultivares do grupo preto e carioca. Dentre estas cultivares, destaca-se a BRS Embaixador, que tem potencial para o mercado externo, sendo caracterizada como grão especial (assim chamado pela sua variedade de cores e maior tamanho, em relação aos grãos consumidos no País, sendo muito demandado pelo mercado internacional). Seu grão é vermelho escuro e o peso de 100 grãos é de $63 \mathrm{~g}$, o que atende ao mercado internacional, e a produtividade média é de $2.214 \mathrm{~kg} \mathrm{ha}^{-1}$ (Silva et al. 2008), sendo que, neste experimento, sua produtividade foi de $2.590 \mathrm{~kg} \mathrm{ha}^{-1}$, evidenciando a viabilidade de produção desta cultura, nas várzeas tropicais.

Os resultados obtidos corroboram os observados por Kluthcouski et al. (2006), especialmente em experimentos conduzidos no município de Lagoa da Confusão (TO), em que a ureia aplicada toda na semeadura, ou seja, a antecipação do N, bem como sua aplicação 10 dias após a emergência do feijoeiro, acarretou maiores produtividades de grãos, em relação à testemunha (sem nitrogênio), sendo mais eficiente que a aplicação aos 20 dias após a emergência das plantas.

\section{Nitrogênio antecipado mais adubação suplementar}

Quanto aos resultados para a combinação de $\mathrm{N}$ antecipado com diferentes fertilizantes, constatou-se, por meio da análise de variância, que houve interação entre os fatores cultivares e fertilizantes, em todos os grupos de cultivares de feijão (Tabela 2). Desta forma, para o grupo preto, deve ser destacada a estabilidade produtiva da cultivar Ouro Negro (2.444-2.940 $\left.\mathrm{kg} \mathrm{ha}^{-1}\right)$, com as maiores produtividades de grãos em 4 dos 5 tratamentos (Tabela 2). Além disto, para as três cultivares, quando houve aplicação de $\mathrm{K}$, constatou-se as maiores produtividades de grãos, com destaque, novamente, para Ouro Negro (2.940 $\left.\mathrm{kg} \mathrm{ha}^{-1}\right)$, superior às demais do grupo 
Tabela 2. Produtividade de grãos de feijoeiro comum irrigado por subirrigação, em função de cultivares e tipos de fertilizantes suplementares aplicados no cultivo de inverno (Lagoa da Confusão, TO, 2008).

\begin{tabular}{|c|c|c|c|c|c|}
\hline \multirow{2}{*}{ Cultivares } & \multicolumn{5}{|c|}{ Fertilização* } \\
\hline & 4. $\mathrm{N}$ ant ${ }^{(1)}$ & 5. $\mathrm{N}$ ant + yoorin $^{(2)}$ & 6. $\mathrm{N}$ ant $+\mathrm{FTE}^{(3)}$ & 7. $\mathrm{N}$ ant $+2 \mathrm{x}$ adub $^{(4)}$ & 8. $\mathrm{N}$ ant $+\mathrm{K}_{2} \mathrm{O}^{(5)}$ \\
\hline Grão tipo preto & \multicolumn{5}{|c|}{ - Produtividade $\left(\mathrm{kg} \mathrm{ha}^{-1}\right)$} \\
\hline BRS Supremo & $2.354 \mathrm{bB} * *$ & $2.560 \mathrm{aA}$ & $2.291 \mathrm{cB}$ & $2.371 \mathrm{cbB}$ & $2.656 \mathrm{bA}$ \\
\hline Ouro Negro & $2.699 \mathrm{aB}$ & $2.510 \mathrm{aC}$ & $2.444 \mathrm{bC}$ & $2.690 \mathrm{aB}$ & $2.940 \mathrm{aA}$ \\
\hline BRS Valente & $2.651 \mathrm{aA}$ & $2.439 \mathrm{aB}$ & $2.682 \mathrm{aA}$ & $2.503 \mathrm{bB}$ & $2.737 \mathrm{bA}$ \\
\hline \multicolumn{6}{|l|}{ Grão tipo carioca } \\
\hline Pitoco & $2.775 \mathrm{aB}$ & $2.447 \mathrm{cC}$ & $2.751 \mathrm{aB}$ & $2.961 \mathrm{aB}$ & $3.109 \mathrm{aA}$ \\
\hline Rudá & $2.536 \mathrm{bcB}$ & $2.795 \mathrm{bA}$ & $2.551 \mathrm{bB}$ & $2.552 \mathrm{bB}$ & $2.836 \mathrm{bA}$ \\
\hline Carioca & $2.580 \mathrm{bB}$ & $2.907 \mathrm{aA}$ & $2.603 \mathrm{bB}$ & $2.845 \mathrm{aA}$ & $2.900 \mathrm{bA}$ \\
\hline BRS Pontal & $2.149 \mathrm{dC}$ & $2.237 \mathrm{deBC}$ & $2.411 \mathrm{cA}$ & $2.375 \mathrm{cA}$ & $2.310 \mathrm{dAB}$ \\
\hline BRS Horizonte & $1.945 \mathrm{eB}$ & $2.013 \mathrm{fB}$ & $2.007 \mathrm{~dB}$ & $1.902 \mathrm{eB}$ & $2.172 \mathrm{eA}$ \\
\hline Pérola & $2.453 \mathrm{cA}$ & $2.341 \mathrm{cdAB}$ & $2.390 \mathrm{cA}$ & $2.266 \mathrm{cB}$ & $2.004 \mathrm{fC}$ \\
\hline Emgopa & $2.037 \mathrm{deD}$ & $2.455 \mathrm{cC}$ & $2.638 \mathrm{abAB}$ & $2.529 \mathrm{bBC}$ & $2.686 \mathrm{cA}$ \\
\hline BRS Requinte & $1.820 \mathrm{fC}$ & $2.130 \mathrm{efB}$ & $2.090 \mathrm{~dB}$ & $2.049 \mathrm{~dB}$ & $2.336 \mathrm{dA}$ \\
\hline \multicolumn{6}{|l|}{ Grão tipo especial } \\
\hline Jalo Precoce & $2.164 \mathrm{bB}$ & $1.924 \mathrm{cC}$ & $2.637 \mathrm{abA}$ & $2.563 \mathrm{ab} \mathrm{A}$ & $2.612 \mathrm{cdA}$ \\
\hline Jalo EEP & $1.368 \mathrm{eC}$ & $1.252 \mathrm{dD}$ & $2.440 \mathrm{cAB}$ & $2.351 \mathrm{cdB}$ & $2.525 \mathrm{dA}$ \\
\hline Iraí & $1.735 \mathrm{dC}$ & $1.833 \mathrm{cC}$ & $2.545 \mathrm{bcB}$ & $2.636 \mathrm{aB}$ & $2.969 \mathrm{bA}$ \\
\hline BRS Radiante & $1.928 \mathrm{cE}$ & $2.129 \mathrm{bD}$ & $2.530 \mathrm{bcB}$ & $2.399 \mathrm{cdC}$ & $2.710 \mathrm{cA}$ \\
\hline BRS Executivo & $1.782 \mathrm{dBC}$ & $1.940 \mathrm{cA}$ & $1.725 \mathrm{eC}$ & $1.934 \mathrm{eA}$ & $1.845 \mathrm{fAB}$ \\
\hline BRS Embaixador & $2.338 \mathrm{aD}$ & $2.357 \mathrm{aCD}$ & $2.742 \mathrm{aB}$ & $2.468 \mathrm{bcC}$ & $3.045 \mathrm{abA}$ \\
\hline WAF 75 & $1.991 \mathrm{cC}$ & $2.160 \mathrm{bB}$ & $2.070 \mathrm{dBC}$ & $2.330 \mathrm{dA}$ & $2.317 \mathrm{eA}$ \\
\hline \multirow[t]{3}{*}{ Cranberry } & $2.248 \mathrm{abC}$ & $2.075 \mathrm{bD}$ & $2.469 \mathrm{cB}$ & $2.448 \mathrm{bcB}$ & $3.130 \mathrm{aA}$ \\
\hline & \multicolumn{5}{|c|}{ Anava (Probabilidade do teste F) } \\
\hline & \multicolumn{2}{|l|}{ Preto } & \multicolumn{2}{|l|}{ Carioca } & Especial \\
\hline Cultivares $(\mathrm{C})$ & \multicolumn{2}{|l|}{$<0,001$} & \multicolumn{2}{|l|}{0,0165} & 0,0203 \\
\hline Fertilização (F) & \multicolumn{2}{|l|}{0,0246} & \multicolumn{2}{|l|}{0,0117} & 0,0298 \\
\hline $\mathrm{C} \times \mathrm{F}$ & \multicolumn{2}{|l|}{0,0184} & \multicolumn{2}{|l|}{0,0317} & 0,0427 \\
\hline C.V. (\%) & \multicolumn{2}{|l|}{4,28} & \multicolumn{2}{|l|}{11,24} & 13,93 \\
\hline \multicolumn{6}{|c|}{ 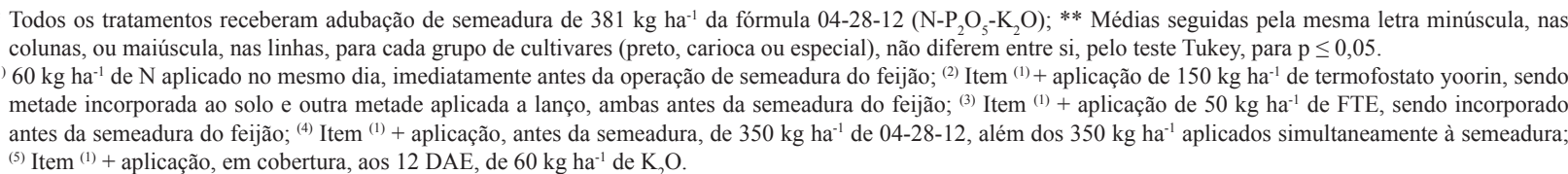 } \\
\hline
\end{tabular}

(2.656 kg ha-1 , para BRS Supremo, e $2.737 \mathrm{~kg} \mathrm{ha}^{-1}$, para BRS Valente), com esta adubação.

A cultivar BRS Valente apresentou produtividade semelhante nas adubações com aplicação de K (2.737 kg ha-1) e de FTE (2682 $\left.\mathrm{kg} \mathrm{ha}^{-1}\right)$, não diferindo do tratamento somente com $\mathrm{N}$ antecipado (2.651 kg ha-1), ou seja, para esta cultivar, não houve incrementos na produtividade, com a adição de outros fertilizantes. Provavelmente, trate-se de uma cultivar com maior rusticidade, apresentando maior capacidade na aquisição de nutrientes.

Com relação às cultivares do grupo carioca (Tabela 2), com exceção da cultivar Pérola $\left(2.004 \mathrm{~kg} \mathrm{ha}^{-1}\right)$, todas as demais alcançaram as maiores produtividades de grãos com a aplicação de $\mathrm{K}$, sendo que, para as cultivares Rudá $(2.836 \mathrm{~kg}$ $\mathrm{ha}^{-1}$, com K, e $2.795 \mathrm{~kg} \mathrm{ha}^{-1}$, com yoorin), Carioca (2.900 kg ha-1, com K; $2.845 \mathrm{~kg} \mathrm{ha}^{-1}$, com $2 \mathrm{x}$ a adubação de semeio; e $2.907 \mathrm{~kg} \mathrm{ha}^{-1}$, com yoorin), BRS Pontal (2.310 kg ha ${ }^{-1}$, com K; $2.375 \mathrm{~kg} \mathrm{ha}^{-1}$, com 2x a adubação de semeio; e $2.411 \mathrm{~kg} \mathrm{ha}^{-1}$, com FTE) e Emgopa (2.686 kg ha-1, com K, e $2.638 \mathrm{~kg} \mathrm{ha}^{-1}$, com FTE), a aplicação de outro fertilizante também proporcionou resultados iguais de produtividade. Quanto à cultivar Pérola, assim como constatado para a BRS Valente, do grupo preto, a simples aplicação de $\mathrm{N}$ antecipado foi suficiente para resultar em maior produtividade de grãos $\left(2.453 \mathrm{~kg} \mathrm{ha}^{-1}\right)$, ou seja, não houve incrementos, com a adição de outros fertilizantes, provavelmente por se tratar de uma cultivar com 
maior eficiência na aquisição dos demais nutrientes. Com a aplicação apenas de $\mathrm{N}$ antecipado, a cultivar Pitoco foi a mais produtiva $\left(2.775 \mathrm{~kg} \mathrm{ha}^{-1}\right)$.

Quanto ao grupo especial (Tabela 2), assim como constatado para o grupo carioca, houve as maiores produtividades de grãos, para todas as cultivares, com a aplicação de K. Contudo, para Jalo Precoce (2.612 $\mathrm{kg} \mathrm{ha}^{-1}$, com K; $2.563 \mathrm{~kg} \mathrm{ha}^{-1}$, com $2 \mathrm{x}$ a adubação de semeadura; e $2.637 \mathrm{~kg} \mathrm{ha}^{-1}$, com FTE), Jalo EEP (2.525 $\mathrm{kg} \mathrm{ha}^{-1}$, com K, e $2.440 \mathrm{~kg} \mathrm{ha}^{-1}$, com FTE), BRS Executivo (1.845 $\mathrm{kg} \mathrm{ha}^{-1}$, com K; $1.934 \mathrm{~kg} \mathrm{ha}^{-1}$, com $2 \mathrm{x}$ a adubação de semeadura; e $1.940 \mathrm{~kg} \mathrm{ha}^{-1}$, com yoorin) e WAF 75 (2.317 $\mathrm{kg} \mathrm{ha}^{-1}$, com K, e $2.330 \mathrm{~kg} \mathrm{ha}^{-1}$, com $2 \mathrm{x}$ a adubação de semeadura), a aplicação de outro fertilizante proporcionou resultados semelhantes à adubação potássica. No tratamento com apenas aplicação de $\mathrm{N}$ antecipado, as cultivares BRS Embaixador (2.338 $\left.\mathrm{kg} \mathrm{ha}^{-1}\right) \mathrm{e}$ Cranberry $\left(2.248 \mathrm{~kg} \mathrm{ha}^{-1}\right)$ foram as mais produtivas, diferindo, estatisticamente, das demais.

Com a fertilização potássica, a cultivar Cranberry (3.130 kg ha-1) destacou-se por apresentar a maior produtividade de grãos (Tabela 2). Villa et al. (2004) relataram que a produtividade do feijoeiro comum, nas várzeas tropicais, foi significativamente aumentada com a aplicação de potássio, apesar dos teores médios e altos de $\mathrm{K}$ disponíveis nos solos. Estes autores ressaltaram que, nestes solos, é provável a obtenção de maiores incrementos na produtividade de grãos com a aplicação de K, do que com a aplicação de fósforo (termofosfato Yoorin), concordando com os resultados obtidos neste experimento.

O potássio tem inúmeras funções na planta, destacando-se, principalmente, a ativação de vários sistemas enzimáticos, muitos deles participantes dos processos de fotossíntese e respiração (Oliveira et al. 2009). Reforçando esta informação, Ramos et al. (2010) relataram que a eficiência de aproveitamento do fósforo pelo feijoeiro, via fertilizante, atinge, no máximo, 20\%. Segundo Andrade et al. (2004), depois do N, o K é o nutriente mais absorvido pela cultura do feijoeiro. Entretanto, Lima et al. (2001) alertaram para a não aplicação de grandes quantidades de adubos potássicos na semeadura, pois podem ocorrer danos às raízes das plantas do feijoeiro.

\section{Grupos de cultivares e formas de adubação}

$\mathrm{Na}$ aplicação de micronutrientes, na forma de fritas FTE BR 12, foram observados aumentos significativos na produtividade de grãos do feijoeiro $\left(2.422 \mathrm{~kg} \mathrm{ha}^{-1}\right)$, sendo superior a quase todos os tratamentos, com exceção do tratamento com a aplicação de $\mathrm{K}_{2} \mathrm{O}\left(2.623 \mathrm{~kg} \mathrm{ha}^{-1}\right)$, que foi inferior, e dos tratamentos em que se aplicou o dobro da adubação $\left(2.430 \mathrm{~kg} \mathrm{ha}^{-1}\right)$, nos quais verificou-se produtividade semelhante (Tabela 3 ).

Existem poucos estudos sobre a aplicação de micronutrientes ao feijoeiro comum, entretanto, Ambrosano et al. (1996 e 1999) também encontraram incrementos positivos na produtividade de grãos desta cultura, com a aplicação de FTE BR 12. Vieira et al. (2011), trabalhando em condições de campo, com a cultivar Ouro Negro (grupo preto), na Zona da Mata de Minas Gerais, em solos de alta fertilidade, não observaram aumento de produtividade do feijoeiro, com o aumento das doses de molibdênio nas sementes. Assim, os resultados observados no presente estudo indicam que existe baixa concentração de micronutrientes nas várzeas do Tocantins e a sua adição, via adubação, proporciona incrementos significativos na produtividade de grãos do feijoeiro.

Adicionalmente, verifica-se que, na região das várzeas tropicais, o clima é quente, implicando em alta taxa de respiração noturna das cultivares, fato que se traduz em reduções de produtividade de grãos (Aidar et al. 2000). Entretanto, estes autores salientam que a produtividade de grãos, apesar de um pouco inferior, devido às condições de clima e do tipo de irrigação, que, juntos, desfavorecem a ocorrência de doenças, pode resultar em redução do custo de produção, justificando a rentabilidade da atividade, mesmo com produtividades relativamente menores.

A produtividade média de grãos de $2.199 \mathrm{~kg} \mathrm{ha}^{-1}$, neste estudo (Tabela 3 ), foi superior à média nacional de $945 \mathrm{~kg} \mathrm{ha}^{-1}$ (Conab 2011), permitindo inferir que a região possui condições propícias à produção de feijão comum, em especial de sementes, pois, durante a condução do experimento, não foi observada incidência de nenhuma doença foliar ou de solo, nas plantas. Entretanto, com maiores doses de N, é possível alcançar produtividades ainda maiores. Santos et al. (2003), trabalhando nas várzeas do Tocantins, obtiveram produtividade de $2.753 \mathrm{~kg} \mathrm{ha}^{-1}$, para a cultivar Pérola, e, utilizando $175 \mathrm{~kg} \mathrm{ha}^{-1} \mathrm{de} \mathrm{N}$, Santos \& Fageria (2008), também em experimentos nas várzeas do Tocantins, com a cultivar Pérola, alcançaram produtividade de $2.678 \mathrm{~kg} \mathrm{ha}^{-1}$, para a dose de $140 \mathrm{~kg} \mathrm{ha}^{-1}$ de N. Cultivares com grãos do tipo preto $\left(2.461 \mathrm{~kg} \mathrm{ha}^{-1}\right)$ resultaram, estatisticamente, 
Tabela 3. Produtividade de grãos de feijoeiro comum irrigado por subirrigação e média de cultivares, em razão da característica do grão, grupo (preto, carioca e especial) e do tipo de fertilização aplicada no cultivo de inverno (Lagoa da Confusão, TO, 2008).

\begin{tabular}{|c|c|c|c|c|c|c|c|c|c|}
\hline Grupo** & 1. Sem $\mathrm{N}^{(1)}$ & 2. $\mathrm{N} \mathrm{cob}^{(2)}$ & $\begin{array}{c}\text { 3. } \mathrm{N} \text { ant }+ \\
\mathrm{N} \mathrm{cob}^{(3)}\end{array}$ & 4. $\mathrm{N}$ ant ${ }^{(4)}$ & $\begin{array}{c}\text { 5. } \mathrm{N} \text { ant }+ \\
\text { Yoorin }^{(5)}\end{array}$ & $\begin{array}{c}\text { 6. } \mathrm{N} \text { ant }+ \\
\mathrm{FTE}^{(6)}\end{array}$ & $\begin{array}{l}\text { 7. } \mathrm{N} \text { ant }+ \\
2 \mathrm{x} \operatorname{adub}^{(7)}\end{array}$ & $\begin{array}{c}\text { 8. } \mathrm{N} \text { ant }+ \\
\mathrm{K}_{2} \mathrm{O}^{(9)}\end{array}$ & $\begin{array}{c}\text { Média } \\
\text { geral }\end{array}$ \\
\hline & \multicolumn{9}{|c|}{ Produtividade* $\left(\mathrm{kg} \mathrm{ha}^{-1}\right)$} \\
\hline Preto & $2.116 \mathrm{a}$ & $2.231 \mathrm{a}$ & $2.499 \mathrm{a}$ & $2.568 \mathrm{a}$ & $2.053 \mathrm{a}$ & $2.472 \mathrm{a}$ & $2.521 \mathrm{a}$ & $2.778 \mathrm{a}$ & $2.461 \mathrm{a}$ \\
\hline Carioca & $1.811 \mathrm{~b}$ & $2.246 \mathrm{a}$ & $2.385 \mathrm{a}$ & $2.287 \mathrm{~b}$ & $2.415 \mathrm{a}$ & $2.430 \mathrm{a}$ & $2.435 \mathrm{a}$ & $2.544 \mathrm{~b}$ & $2.319 \mathrm{~b}$ \\
\hline Especial & $1.193 \mathrm{c}$ & $1.669 \mathrm{~b}$ & $1.656 \mathrm{~b}$ & $1.944 \mathrm{c}$ & $1.959 \mathrm{~b}$ & $2.395 \mathrm{a}$ & $2.391 \mathrm{a}$ & $2.644 \mathrm{~b}$ & $1.981 \mathrm{c}$ \\
\hline \multirow[t]{2}{*}{ Média } & $1.599 \mathrm{~F}$ & $2.001 \mathrm{E}$ & $2.096 \mathrm{D}$ & $2.187 \mathrm{C}$ & $2.237 \mathrm{C}$ & $2.422 \mathrm{~B}$ & $2.430 \mathrm{~B}$ & $2.623 \mathrm{~A}$ & 2.199 \\
\hline & \multicolumn{9}{|c|}{ Anava (Probabilidade do teste F) } \\
\hline Grupo (G) & \multicolumn{9}{|c|}{$<0,001$} \\
\hline Fertilização (F) & \multicolumn{9}{|c|}{$<0,001$} \\
\hline $\mathrm{G} \times \mathrm{F}$ & \multicolumn{9}{|c|}{0,0498} \\
\hline C.V. $(\%)$ & \multicolumn{9}{|c|}{19,24} \\
\hline
\end{tabular}

* Médias seguidas pela mesma letra minúscula, nas colunas, ou maiúscula, nas linhas, não diferem entre si, pelo teste Tukey, para $\mathrm{p}<0,05$; ** Preto corresponde à média das cultivares BRS Supremo, Ouro Negro e BRS Valente; carioca à média das cultivares Pitoco, Rudá, Carioca, BRS Pontal, BRS Horizonte, Pérola, Emgopa e BRS Requinte; e especial à média das cultivares Jalo Precoce, Jalo EEP, Iraí, BRS Radiante, BRS Executivo, BRS Embaixador, WAF 75 e Cranberry.

(1) Sem N: sem nitrogênio (N); ${ }^{(2)} 60 \mathrm{~kg} \mathrm{ha}^{-1}$ de $\mathrm{N}$ incorporado em cobertura, aos 12 dias após a emergência (DAE) do feijão; ${ }^{(3)} 30 \mathrm{~kg}$ ha ${ }^{-1}$ de $\mathrm{N}$ aplicado no mesmo dia, imediatamente antes da operação de semeadura do feijão, e $30 \mathrm{~kg} \mathrm{ha}^{-1}$ de $\mathrm{N}$ incorporado em cobertura, aos $12 \mathrm{DAE}$; ${ }^{(4)} 60 \mathrm{~kg}$ ha-1 de $\mathrm{N}$ aplicado no mesmo dia, imediatamente antes da operação de semeadura do feijão; ${ }^{(5)}$ Item $^{(4)}+$ aplicação de $150 \mathrm{~kg} \mathrm{ha}^{-1}$ de termofostato yoorin, sendo metade incorporada ao solo e a outra metade aplicada a lanço, ambas antes da semeadura do feijão; ${ }^{(6)}$ Item $^{(4)}+$ aplicação de $50 \mathrm{~kg} \mathrm{ha}^{-1}$ de FTE, sendo incorporado antes da semeadura do feijão; ${ }^{(7)}$ Item ${ }^{(4)}+$

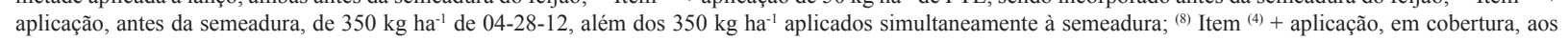
$12 \mathrm{DAE}$, de $60 \mathrm{~kg} \mathrm{ha}^{-1}$ de $\mathrm{K}_{2} \mathrm{O}$.

em maiores produtividades, seguidas por cultivares com grãos do tipo carioca $\left(2.319 \mathrm{~kg} \mathrm{ha}^{-1}\right)$ e especial $\left(1.981 \mathrm{~kg} \mathrm{ha}^{-1}\right)$.

\section{CONCLUSÕES}

1. Com relação à época de aplicação de fertilizantes nitrogenados, a produtividade de grãos do feijoeiro foi maior com a antecipação da adubação nitrogenada, e ainda maior quando esta foi combinada com a suplementação de potássio em cobertura, sendo que Ouro Negro (grupo preto), Pitoco (grupo carioca) e Cranberry e BRS Embaixador (grupo especial) foram as cultivares mais produtivas.

2. Com a utilização somente da adubação recomendada, as cultivares Ouro Negro (grupo preto), Carioca (grupo carioca) e Jalo Precoce e BRS Embaixador (grupo especial) foram as mais produtivas.

3. Para as condições de várzea irrigada, as cultivares do grupo preto foram mais produtivas que as dos grupos carioca e especial.

\section{AGRADECIMENTOS}

À Empresa Brasileira de Pesquisa Agropecuária (Embrapa), pelo financiamento da pesquisa e pela bolsa de doutorado concedida ao primeiro autor; ao Conselho Nacional de Desenvolvimento Científico e Tecnológico (CNPq), pela bolsa de produtividade em pesquisa concedida ao terceiro autor; ao técnico agrícola Floriano Resende e aos operários rurais João Batista Monteiro e Luiz Lopes da Silva, pelo auxílio na condução dos trabalhos.

\section{REFERÊNCIAS}

AFONSO, R. J. et al. Combinações de nitrogênio no desenvolvimento e rendimento do feijoeiro. Pesquisa Agropecuária Tropical, Goiânia, v. 41, n. 3, p. 391-398, 2011.

AIDAR, H. et al. Bean production and white mould incidence under no-till system. Annual Report of the Bean Improvement Cooperative, East Lansing, v. 43, n. 1, p. 150-151, 2000.

AIDAR, H. et al. Estabelecimento da cultura. In: AIDAR, H. et al. (Eds.). Produção do feijoeiro comum em várzeas tropicais. Santo Antônio de Goiás: Embrapa Arroz e Feijão, 2002. p. 105-119.

AMBROSANO, E. J. et al. Efeitos da adubação nitrogenada e com micronutrientes na qualidade de sementes do feijoeiro cultivar IAC-Carioca. Bragantia, Campinas, v. 58, n. 2, p. 393-399, 1999.

AMBROSANO, E. J. et al. Resposta da aplicação de micronutrientes no cultivo de feijão irrigado no inverno. Scientia Agricola, Piracicaba, v. 53, n. 2-3, p. 273-279, 1996. 
ANDRADE, C. A. B. et al. Produtividade e qualidade nutricional de cultivares de feijão em diferentes adubações. Ciência e Agrotecnologia, Lavras, v. 28, n. 5, p. 10771086, 2004.

ARF, M. V. et al. Fontes e épocas de aplicação de nitrogênio em feijoeiro de inverno sob sistema plantio direto. Pesquisa Agropecuária Tropical, Goiânia, v. 41, n. 3, p. 430-438, 2011.

BARBOSA, R. M. et al. Nitrogênio na produção e qualidade de sementes de feijão. Pesquisa Agropecuária Tropical, Goiânia, v. 41, n. 3, p. 470-474, 2011.

BINOTTI, F. F. S. et al. Manejo do solo e da adubação nitrogenada na cultura de feijão de inverno e irrigado. Bragantia, Campinas, v. 66, n. 1, p. 121-129, 2007.

COMPANHIA NACIONAL DE ABASTECIMENTO (Conab). Acompanhamento da safra brasileira: grãos, segundo levantamento, novembro 2011. 2011. Disponível em: <http://www.conab.gov.br/OlalaCMS/ uploads/arquivos/11_11_09_11_49_48_boletim_2o_ levantamento_safra_2011_12.pdf $>$. Accesso em: 21 nov. 2011.

CRUSCIOL, C. A. C. et al. Fontes e doses de nitrogênio para o feijoeiro em sucessão a gramíneas no sistema plantio direto. Revista Brasileira de Ciência do Solo, Viçosa, v. 31, n. 6, p. 1545-1552, 2007.

EMPRESA BRASILEIRA DE PESQUISA AGROPECUÁRIA (Embrapa). Centro Nacional de Pesquisa de Solos. Sistema brasileiro de classificação de solos. Rio de Janeiro: Embrapa Solos, 1999.

FAGERIA, N. K. et al. Caracterização química e granulométrica de solos de várzea de alguns Estados brasileiros. Pesquisa Agropecuária Brasileira, Brasília, DF, v. 29, n. 2, p. 267-274, 1994.

FARINELLI, R. et al. Produtividade e qualidade fisiológica de sementes de feijão em função de sistemas de manejo de solo e adubação nitrogenada. Revista Brasileira de Sementes, Londrina, v. 28, n. 2, p. 102-109, 2006a.

FARINELLI, R. et al. Adubação nitrogenada de cobertura no feijoeiro, em plantio direto e convencional. Pesquisa Agropecuária Brasileira, Brasília, DF, v. 41, n. 2, p. 307312, 2006b.

KLUTHCOUSKI, J. et al. Manejo antecipado do nitrogênio nas principais culturas anuais. Santo Antônio de Goiás: Embrapa Arroz e Feijão, 2006. (Documentos, 188).

LIMA, E. V. et al. Adubação NK no desenvolvimento e na concentração de macronutrientes no florescimento do feijoeiro. Scientia Agricola, Piracicaba, v. 58, n. 1, p. 125-129, 2001.

MEIRA, F. A. et al. Doses e épocas de aplicação de nitrogênio no feijoeiro irrigado cultivado em plantio direto.
Pesquisa Agropecuária Brasileira, Brasília, DF, v. 40, n. 4, p. 383-388, 2005.

MIRANDA, L. N. et al. Produtividade do feijoeiro em resposta a adubação fosfatada e a regime de irrigação em solo de Cerrado. Pesquisa Agropecuária Brasileira, Brasília, DF, v. 35, n. 4, p.703-710, 2000.

OLIVEIRA, A. P. et al. Rendimento produtivo e econômico do feijão-caupi em função de doses de potássio. Ciência e Agrotecnologia, Lavras, v. 33, n. 2, p. 629-634, 2009.

OLIVEIRA, P. et al. Sistema Santa Brígida - Tecnologia Embrapa: consorciação de milho com leguminosas. Santo Antônio de Goiás: Embrapa Arroz e Feijão, 2010. (Circular técnica, 88).

RAMOS, S. J. et al. Utilização de fósforo e produção do feijoeiro: influência de gramíneas forrageiras e fontes de fósforo. Revista Brasileira de Ciência do Solo, Viçosa, v. 34, n. 1, p. 89-96, 2010.

SANT'ANA, E. V. P. et al. Adubação nitrogenada na produtividade, leitura SPAD e teor de nitrogênio em folhas de feijoeiro. Pesquisa Agropecuária Tropical, Goiânia, v. 40, n. 4, p. 491-496, 2010.

SANTOS, A. B. et al. Resposta do feijoeiro ao manejo de nitrogênio em várzeas tropicais. Pesquisa Agropecuária Brasileira, Brasília, DF, v. 38, n. 11, p. 1265-1271, 2003.

SANTOS, A. B.; FAGERIA, N. K. Características fisiológicas do feijoeiro em várzeas tropicais afetadas por doses e manejo de nitrogênio. Ciência e Agrotecnologia, Lavras, v. 32, n. 1, p. 23-31, 2008.

SILVA, C. C. et al. Feijão comum cultivar BRS Embaixador: espaçamento e densidade de semeadura. Santo Antônio de Goiás: Embrapa Arroz e Feijão, 2008. (Circular técnica, 80).

SORATTO, R. P. et al. Aplicação tardia de nitrogênio no feijoeiro em sistema de plantio direto. Bragantia, Campinas, v. 64, n. 2, p. 211-218, 2005.

SORATTO, R. P. et al. Resposta do feijoeiro ao preparo do solo, manejo de água e parcelamento do nitrogênio. Acta Scientiarum Agronomy, Maringá, v. 25, n. 1, p. 8996, 2003.

SOUSA, D. M. G.; LOBATO, E. Cerrado: correção do solo e adubação. Planaltina, DF: Embrapa Cerrados, 2003.

VALDERRAMA, M. et al. Fontes e doses de nitrogênio e fósforo em feijoeiro no sistema plantio direto. Pesquisa Agropecuária Tropical, Goiânia, v. 39, n. 3, p. 191-196, 2009.

VIEIRA, R. F. et al. Aplicação foliar de molibdênio em feijoeiro: conteúdo do nutriente na semente e desempenho das plantas originadas. Pesquisa Agropecuária Tropical, Goiânia, v. 41, n. 2, p. 163-169, 2011.

VILLA, M. R. L. et al. Formas de potássio em solos de várzea e sua disponibilidade para o feijoeiro. Revista Brasileira de Ciência do Solo, Viçosa, v. 28, n. 4, p. 649658, 2004. 